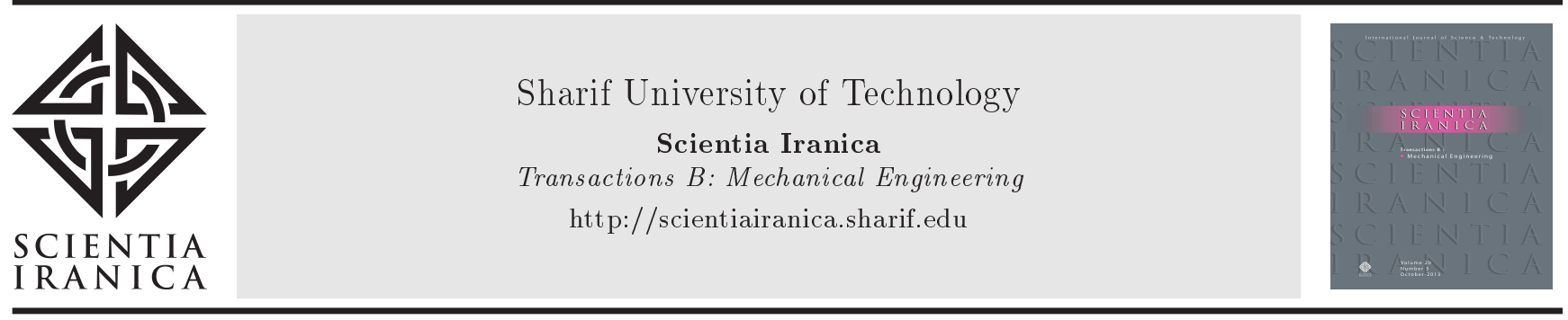

\title{
Experimental and numerical study of low frequency pulsed Nd:YAG laser heating of slip cast fused silica ceramics for laser assisted turning process considering laser beam overlapping
}

\author{
H. Roostai ${ }^{a}$, M.R. Movahhedy ${ }^{a, *}$, and R. Shoja Razavi ${ }^{b}$ \\ a. Department of Mechanical Engineering, Sharif University of Technology, Tehran, Iran. \\ b. Department of Materials Science, Malek-Ashtar University, ShahinShahr, Iran.
}

Received 20 February 2018; accepted 9 October 2018

\section{KEYWORDS}

Pulsed Nd:YAG laser;

Slip cast fused silica

ceramic;

Finite-element

method;

Laser overlapping;

Laser heating.

\begin{abstract}
Machining of ceramics often involves many challenges due to their high hardness, brittleness, and low-thermal conductivity. Laser Assisted Machining (LAM) is a promising technology for improving the machinability of hard-to-cut materials. In this work, the effect of laser heating in the LAM process on Slip Cast Fused Silica (SCFS) ceramics is investigated by conducting a numerical thermal analysis of laser effects on material behavior. A transient three-dimensional heat transfer analysis for Laser Assisted Turning (LAT) of SCFS is performed using finite-element method. Temperature distributions in SCFS cylindrical specimens are obtained. Moreover, the influence of laser parameters, such as power, translational speed, and feed rate, on the temperature field is studied. To increase the absorptivity of the ceramic surface, a coating is applied, and the absorptivity of the coated surface is determined by carrying out a series of experiments. Experiments are performed to validate the numerical transient heat transfer finite-element model. In addition, the effects of spot overlapping of pulsed laser on temperature distribution and absorptivity of SCFS workpiece are studied. It is for the first time that effect of laser beam overlapping on low frequency pulsed laser heating in LAT is formulated and completely investigated.

(C) 2019 Sharif University of Technology. All rights reserved.
\end{abstract}

\section{Introduction}

Conventional grinding and diamond machining are the most widely used machining methods in the manufacturing processes of ceramic products due to their inherent hardness and brittle nature. High machining cost and low material removal rates can be mentioned

\footnotetext{
*. Corresponding author.

E-mail addresses: roostai@mech.sharif.ir (H. Roostai);

movahhed@sharif.edu (M.R. Movahhedy);

shoja_r@yahoo.com (R.Shoja Razavi)
}

doi: $10.24200 /$ sci. 2018.50481 .1715 as the main drawbacks of both of the machining procedures. Hence, conventional machining of ceramics is time consuming and inefficient. Moreover, other challenging problems, such as surface and subsurface damages, are often endemic in ceramic machining due to their brittleness. Therefore, an alternative technique must be applied to increase productivity while reducing time and cost of manufacturing.

In recent years, the LAM process has been introduced as an alternative method, which can be used effectively in machining of hard-to-cut materials. LAM combines local heating of laser with conventional machining techniques such as grinding [1], milling $[2,3]$, 
turning [4-7], drilling [8], and planning [9]. As a result of local heating, the hard material is softened and its machinability is improved, leading to higher productivity.

In the area of ceramic machining, the effectiveness of LAM process has been investigated previously by several researchers. A review of major works in this area is presented in the following. Rebro et al. [10] determined operating conditions for crack-free LAT of mullite by applying a $\mathrm{CO}_{2}$ laser. They reported longer tool life and lower cutting forces in LAT compared to conventional machining. They also stated that among various laser power profiles, only the two-ramped profile prevented the occurrence of thermal fracture and crack formation. Chang and Kuo [9] studied LAM of $\mathrm{Al}_{2} \mathrm{O}_{3}$ ceramics planning using a $25 \mathrm{~W}$ continuous wave $\mathrm{CO}_{2}$ laser. They observed that LAM reduced cutting forces by about $10-16 \%$ and surface roughness was much better than that in conventional machining. In another study, Chang and Kuo [11] utilized a $60 \mathrm{~W}$ pulsed wave $\mathrm{Nd}$ :YAG laser in LAT of $\mathrm{Al}_{2} \mathrm{O}_{3}$ ceramics. Experimental measurements of surface roughness were evaluated using Taguchi method. Their results showed that the best operating conditions obtained by the Taguchi method had a significant improvement in workpiece quality. Tian and Shin [12] employed a $1.5 \mathrm{~kW}$ continuous wave $\mathrm{CO}_{2}$ laser to investigate LAT of silicon nitride ceramics with complex geometrical features. They reported that LAM provided good surface finish and tool life that is comparable to metal cutting. Kim et al. [13] investigated LAM for silicon nitride ceramics using a $2.5 \mathrm{~kW}$ High Power Diode Laser (HPDL). By controlling laser power, the Cubic Boron Nitride (CBN) cutting tool cut the material easily; however, excessive oxidation reduced the quality of the material surface as the temperature increased. Pfefferkorn et al. [14] researched the LAM of magnesiapartially-stabilized zirconia. They showed that LAM of this material could be performed without fracturing the workpiece. In addition, Pfefferkorn et al. [15] studied thermally assisted turning of silicon nitride and Partially-Stabilized Zirconia (PSZ) ceramics using a continuous wave $\mathrm{CO}_{2}$ laser. They introduced a specific thermal energy, minimum preheating power, and preheating efficiency metric to define the energy efficiency of thermally assisted machining. Rozzi et al. [16] performed some experiments on LAM of silicon nitride ceramics with a wide range of operating conditions. For temperatures above the glass transition temperature, they showed that chips were continuous or semicontinuous. Tian and Shin [17] developed a multi-scale finite-element model to simulate LAM of silicon nitride ceramics. They used interfacial cohesive elements to model intergranular glass phase of silicon nitride. The use of LAM resulted in crack-free subsurfaces for silicon nitride workpieces. In a study similar to the previous one, Dong and Shin [18] utilized multi-scale finite-element modeling for LAM of alumina ceramics. They represented that LAM decreased cutting forces and improved the machinability of the material in comparison with conventional machining.

Previous investigators have developed thermal models for LAM of ceramic materials. A transient thermal finite volume model (without material removal) for rotating cylindrical silicon nitride workpiece subjected to a translating $\mathrm{CO}_{2}$ laser was represented by Rozzi et al. [19]. The model considered thermal conductivity as well as heat radiation and convection from rotating part to the ambient air. In order to evaluate the modeling results, the surface temperature was measured using a laser pyrometer. Using the model in [19], Rozzi et al. [20] studied the effect of operating parameters on thermal conditions within a workpiece. In addition, Rozzi et al. [21,22] presented a transient three-dimensional thermal model, which included material removal, too. Rebro et al. [10] modified the model of Rozzi et al. [22] to investigate mullite ceramics with different thermo-physical properties. Pfefferkorn et al. [23] presented a heat transfer model for LAM of PSZ as a semi-transparent ceramic. The important parameters required for modelling semi-transparent materials include internal radiation, convection, and diffusion. The authors utilized diffusion approximation to determine internal radiation, which was assessed by comparing predictions (based on an optically thick assumption) with results from discrete ordinates method.

SCFS is a widely used ceramic material that is usually cut using conventional grinding. This amorphous ceramic is a porous and optically opaque with white body. SCFS ceramics possess favorable properties such as high resistance to thermal shock as well as proper electromagnetic characteristics [24]. Because of low thermal expansion of SCFS ceramics, little thermal stresses are produced due to thermal shocks to the material; consequently, little strength is needed to resist these stresses [25]. Machining SCFS ceramics is often performed by diamond grinding at low wheel speeds and low material feed rates. Due to the low tensile strength of SCFS ceramic, high feed rates can cause tensile failure in the SCFS part. A preliminary study of heat transfer in LAM of SCFS ceramics was presented by current authors [26], which demonstrated the effectiveness of this process.

Pulse overlapping is an important parameter that influences the properties of surfaces exposed to laser pulses. A number of researchers have studied this parameter. Huang et al. [27] enhanced optical and electrical properties of Al-doped $\mathrm{ZnO}$ coated polyethylene terephthalate substrates by utilizing an overlap rate controlling strategy in laser annealing. Hafiz et al. [28] analyzed the effect of overlapping on the surface quality of AISI H13 tool steel in laser polishing. They 
concluded that an overlap percentage of $95 \%$ reduced both the waviness and roughness components of initial surface topography. In addition, $\mathrm{Hu}$ and Yao [29] applied finite-element method to simulate the effect of overlapping laser shock processing in order to increase the compressive residual stresses, which improved fatigue, corrosion, and wear resistance of metals. In addition, laser spot overlapping in LAM can change the absorptivity of surfaces, especially for workpieces with nondurable and temperature-dependent surface properties. Furthermore, laser spot overlapping was considered in some other machining studies [30].

The present study explores the transient heat transfer in SCFS ceramics for the purpose of LAM of this material. Results from the numerical model of laser heating for different heating conditions are compared with those from the experimental tests. In this regard, the laser heat source is provided by a pulsed Nd:YAG laser. This solid state laser has notable properties such as high beam intensity at low mean beam power, good focusing characteristics, and narrow heat affected zones [31]. Temperature distribution in SCFS ceramics due to laser heating is obtained using finite element method. In addition, pulse overlapping rates for LAT are formulated, and the effects of laser spot overlapping on the workpiece absorptivity and on temperature distribution in the workpiece are investigated. Furthermore, operational conditions for favorable LAT procedure are proposed. Since the focus of the work is on the thermal effects, the material removal phase is not included in the model.

\section{Experimental setup}

The experimental equipment employed for the LAM of SCFS ceramics is depicted in Figure 1, while Figure 2 shows a schematic view of laser heating configuration. The laser heat source is a pulsed-wave Nd:YAG (Neodinium-doped $\left(\mathrm{ND}^{3+}\right)$ : Yttrium-Aluminum-

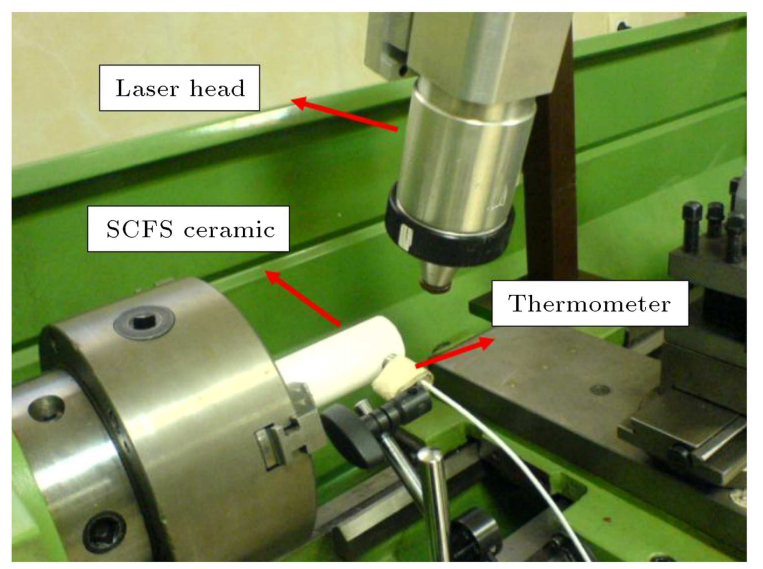

Figure 1. Experimental facility for the LAM of SCFS ceramics.

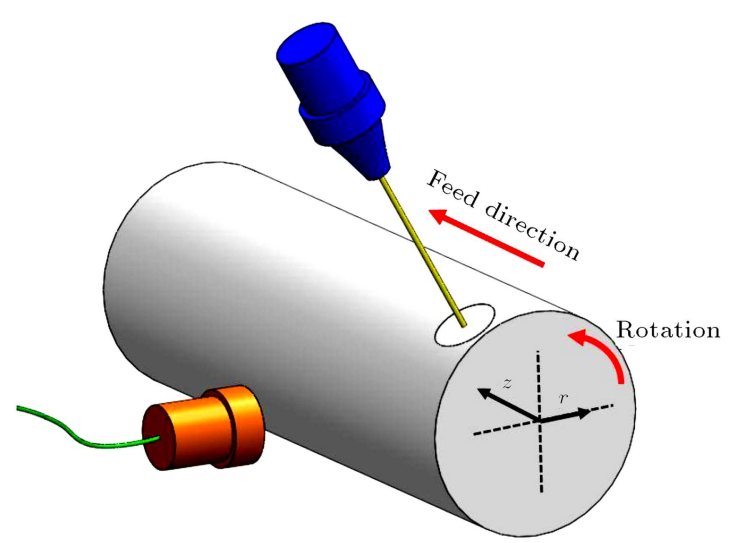

Figure 2. Schematic of laser heating configuration.

Garnet (YAG)) laser (wavelength of $1.06 \mu \mathrm{m}$ ) Model IQL-20 with a maximum average power of $750 \mathrm{~W}$. The ranges of pulse frequency, pulse energy, and pulse duration of the laser are 1-250 Hz, 0-40 J, and 0.2-25 $\mathrm{ms}$, respectively. The heating operation is performed on a $2 \mathrm{hp} \mathrm{Shimato} \mathrm{metal} \mathrm{cutting} \mathrm{lathe} \mathrm{model} \mathrm{CO636A.}$ Cylindrical SCFS specimens are used with a diameter of $35 \mathrm{~mm}$ and length of $100 \mathrm{~mm}$. The alignment of the workpiece in the 3 -jaw chuck is achieved using a dial gauge. Temperature measurements are performed using micro-epsilon CT-SF02-C3 thermometer. The values of these non-contact infrared thermometer parameters range from -50 to $600^{\circ} \mathrm{C}$ for temperature, $\pm 0.1^{\circ} \mathrm{C}$ for temperature resolution, $150 \mathrm{~ms}$ for response time, and $2 \mathrm{~mm}$ for the smallest spot size (for which the distance between the workpiece and the thermometer is $25 \mathrm{~mm}$ ). The laser beam is delivered through a fiber optic cable to the lathe and is stroked on the surface of workpiece at an angle of nearly $73^{\circ}$ circumferentially ahead of the thermometer.

\section{Simulation procedure}

The heat transfer in the cylindrical SCFS workpiece occurs in three major modes: (1) thermal conduction through the workpiece; (2) natural convection heat loss to ambient air from the workpiece surfaces; and (3) thermal radiation between the workpiece surfaces and the surroundings.

\subsection{Transient heat transfer formulation}

The governing transient three-dimensional heat equation of a rotating cylinder in a nonrotating cylindrical coordinate system $(r, \varphi, z)$ can be written as follows [19]:

$$
\begin{gathered}
\frac{1}{r} \frac{\partial}{\partial r}\left(k r \frac{\partial T}{\partial r}\right)+\frac{1}{r^{2}} \frac{\partial}{\partial \varphi}\left(k \frac{\partial T}{\partial \varphi}\right)+\frac{\partial}{\partial z}\left(k \frac{\partial T}{\partial z}\right) \\
-\frac{\partial\left(\rho \omega c_{p} T\right)}{\partial \varphi}-\frac{\partial\left(\rho \omega c_{p} T\right)}{\partial \varphi}=0,
\end{gathered}
$$

where $k, \rho, c_{p}, \omega, T$, and $t$ are thermal conductivity 
$(\mathrm{W} / \mathrm{m} \mathrm{K})$, density $\left(\mathrm{kg} / \mathrm{m}^{3}\right)$, specific heat capacity at constant pressure $(\mathrm{J} / \mathrm{kg} \mathrm{K})$, rotational speed of the workpiece $(\mathrm{rad} / \mathrm{s})$, temperature $(\mathrm{K})$, and time $(\mathrm{s})$, respectively. The boundary conditions for Eq. (1) are as follows:

$$
\begin{aligned}
& \left.k \frac{\partial T}{\partial r}\right|_{r=R}=\alpha q_{l}^{\prime \prime}-q_{\text {conv }}^{\prime \prime}-\varepsilon \sigma\left(T(R, \varphi, z)-T_{\text {sur }}\right)^{4} \\
& \left.k \frac{\partial T}{\partial r}\right|_{r=R}=-q_{\text {conv }}^{\prime \prime}-\varepsilon \sigma\left(T(R, \varphi, z)-T_{\text {sur }}\right)^{4} \\
& \left.k \frac{\partial T}{\partial z}\right|_{z=0}=q_{\text {conv }}^{\prime \prime}+\varepsilon \sigma\left(T(R, \varphi, z)-T_{\text {sur }}\right)^{4} \\
& \left.k \frac{\partial T}{\partial z}\right|_{z=L}=0
\end{aligned}
$$

in which:

$$
q_{\text {conv }}^{\prime \prime}=h_{\text {conv }}\left(T(R, \varphi, z)-T_{\infty}\right),
$$

where $R, \alpha, q_{l}^{\prime \prime}, q_{\text {conv }}^{\prime \prime}, \varepsilon, \sigma, T_{\text {sur }}, L, h_{\text {conv }}$, and $T_{\infty}$ are the workpiece radius $(\mathrm{m})$, the absorptivity of the workpiece surface to $\mathrm{Nd}$ :YAG laser irradiation, the laser heat flux $\left(\mathrm{W} / \mathrm{m}^{2}\right)$, the convective heat flux $\left(\mathrm{W} / \mathrm{m}^{2}\right)$, the total emissivity of the workpiece surface, Stefan-Boltzman constant $\left(5.670367 \mathrm{e}-8 \mathrm{~W} / \mathrm{m}^{2} \mathrm{~K}^{4}\right)$, the surroundings temperature, the workpiece length $(\mathrm{m})$, the convective heat transfer coefficient $\left(\mathrm{W} / \mathrm{m}^{2} \mathrm{~K}\right)$, and the ambient air temperature, respectively. Eq. (2a) should be satisfied on the laser spot, while Eq. (2b) represents the boundary conditions for the rest of the cylindrical surface. In addition, Eqs. (3) and (4) express the boundary conditions on the free and fixed ends of the workpiece, respectively (assumed as an adiabatic surface). The initial condition of the workpiece at time $t=0$ is of the form:

$$
T(R, \varphi, z, 0)=T_{\infty} .
$$

The transverse electromagnetic mode of laser beams is represented by $\mathrm{TEM}_{m n}$, in which $m$ and $n$ correspond to the number of nodes on the plane perpendicular to the beam propagation direction. In laser machining applications, the fundamental mode, $\mathrm{TEM}_{00}$, with a Gaussian spatial distribution is often used [32]. The two-dimensional Gaussian distribution of laser heat flux on an $x-y$ flat plane can be represented as follows:

$$
q_{l}^{\prime \prime}(x, y)=I_{0} \exp \left(-\frac{2\left(x^{2}+y^{2}\right)}{w^{2}}\right),
$$

in which:

$$
I_{0}=\frac{2 P}{\pi w^{2}}
$$

$$
P=E_{p} H
$$

where $I_{0}, w, P, E_{p}$, and $H$ are the intensity scale factor $\left(\mathrm{W} / \mathrm{m}^{2}\right)$, the laser beam radius at which $q_{l}^{\prime \prime} / I_{0}=$ $1 / e^{2}$, the incident laser average power (W), the energy per pulse $(\mathrm{J})$, and the frequency of laser pulse $(\mathrm{Hz})$, respectively. Of note, the maximum value of laser heat flux occurs at the center of the incident beam.

Convective heat transfer coefficient for a cylinder rotating around its axis without applying laser assisted air jet (natural convection) can be expressed as follows:

$$
h_{\text {conv }}=\kappa \mathrm{Nu} / D \text {, }
$$

where $\mathrm{Nu}, \kappa$, and $D$ are the Nusselt number, the thermal conductivity of the air, and the workpiece diameter, respectively. Mohanty et al. [33] obtained the total average Nusselt number for a rotating cylinder in quiescent air as follows:

$$
\mathrm{Nu}=0.38 \operatorname{Re}^{0.58}
$$

in which:

$$
\operatorname{Re}=R D \omega / \nu
$$

where Re and $\nu$ are the Reynolds number and the kinematic viscosity of the air $\left(\mathrm{m}^{2} / \mathrm{s}\right)$, respectively. In Eq. (11), Re varies from 400 to $10^{5}$ with a maximum deviation of $14 \%$ [33].

\subsection{Thermo-physical properties of SCFS ceramics}

The properties of the SCFS materials required for thermal analysis are temperature dependent including specific heat capacity, thermal conductivity, and density. Figure 3 shows the variation of specific heat capacity and thermal conductivity of SCFS ceramics versus temperature, and the variation of density of these ceramics versus temperature is depicted in Figure 4 . It can be observed from these figures that specific heat

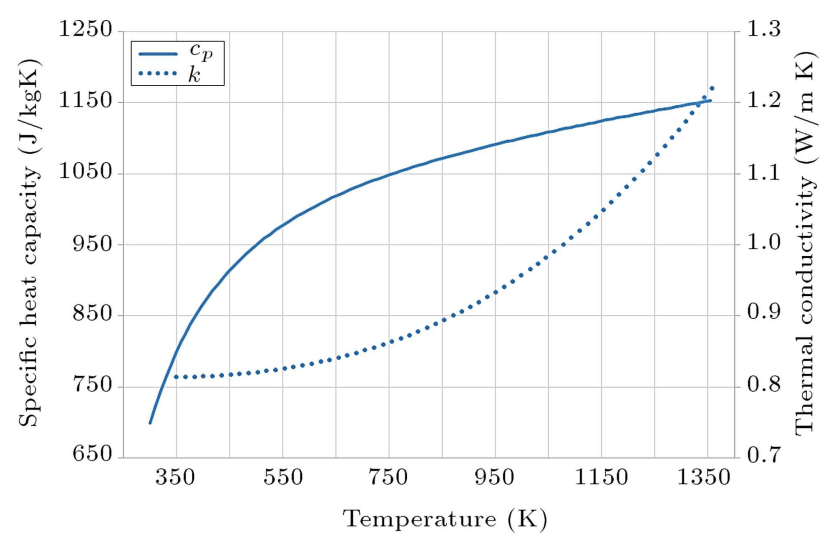

Figure 3. Specific heat capacity and thermal conductivity of SCFS ceramics versus temperature [35]. 


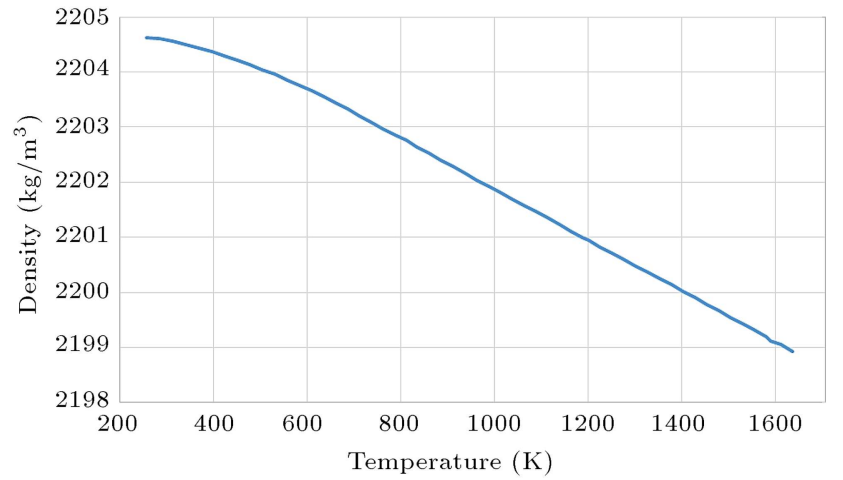

Figure 4. Density of SCFS ceramics versus temperature [35].

capacity and thermal conductivity of SCFS ceramic increase with temperature, while its density decreases. A high reflectivity value of 0.94 for SCFS ceramic was reported by Bohn and Wang [34]. For all materials which can be considered opaque (such as SCFS ceramic due to its zero transmissivity), the relation between reflectivity and absorptivity is of the following form:

$$
\alpha+\tau=1
$$

where $\tau$ is the reflectivity of the workpiece surface. An estimated value of the emissivity of SCFS ceramics varies from 0.60 at $1590 \mathrm{~K}$ to 0.72 at $1920 \mathrm{~K}$ [35]. However, this temperature range is much higher than the desired operating temperature range of the workpiece surface; consequently, a correct emissivity value could not be obtained. Due to the lack of a specified emissivity value, it is assumed that the workpiece surfaces have diffuse and gray behavior (i.e., $\alpha=\varepsilon$ ).

\subsection{Finite-element analysis}

Numerical simulations of the transient heat transfer of LAM of SCFS ceramics are performed using a threedimensional finite-element model. These simulations are carried out with the commercial finite-element ABAQUS/Standard software. The laser beam heat flux is implemented in a FORTRAN user subroutine, named DFLUX, which is developed to define nonuniform distributed heat flux as a function of time. The cylindrical workpiece is modeled with eight-node linear heat transfer brick elements (DC3D8 in ABAQUS software). Although smaller mesh size increases the accuracy of numerical results, it leads to higher computation cost. Consequently, a suitable mesh size is adopted as a trade-off between accuracy and cost. On the other hand, an appropriate time step selection is required for each transient heat transfer problem. The size of time steps should be determined by considering the pulse frequency and the pulse duration of the laser. A small enough time step is needed in order to achieve convergence.

\subsection{Pulse overlapping rates for $L A T$}

The overlap rates of laser pulses are usually defined by laser spot overlap rate and laser scan line overlap rate (see Figure 5). Both of these overlap rates are linear functions of the distance between two adjacent laser spots. In Figure 5, diagonal and parallel hatchings are used to represent laser spot overlap and laser scan line overlap, respectively. Alternative definitions of the overlap rates are obtained by the ratio of the overlapping area to the area of a spot. These definitions are more accurate than the previous definitions for complicated overlapping patterns. In LAT, the laser spots distribution pattern can be mapped on a $2 \mathrm{D}$ plane with a length of $L$ (which equals the length of the workpiece) and width of $\pi D$ (which equals the perimeter of the base of the cylindrical workpiece). Figure 6 shows a 2D schematic view of laser spots distribution pattern on the surface irradiated with a pulsed laser. In this figure, the laser spots are assumed circular, and laser moves in an oblique direction over the plane to account for the feed motion. It can be observed from the figure that every irradiated laser spot over the plane overlaps with the previous spot as well as the adjacent spots from the previous revolution.

\subsubsection{Laser spot overlap rate}

Overlapping rate for two adjacent laser spots can be expressed as follows (see Figure 7):

$$
\begin{aligned}
O R= & \frac{S_{s}}{S_{c}} \times 100 \% \\
= & \left(\frac{2}{\pi} \tan ^{-1} \sqrt{\frac{4 w^{2}-\Delta^{2}}{\Delta^{2}}}-\frac{\Delta}{2 \pi w^{2}} \sqrt{4 w^{2}-\Delta^{2}}\right) \\
& \times 100 \%=O R(w, \Delta)
\end{aligned}
$$

where $S_{s}, S_{c}$, and $\Delta$ are the area of overlapping between two adjacent spots, the spot area, and the overlap length of two spots, respectively. The vector

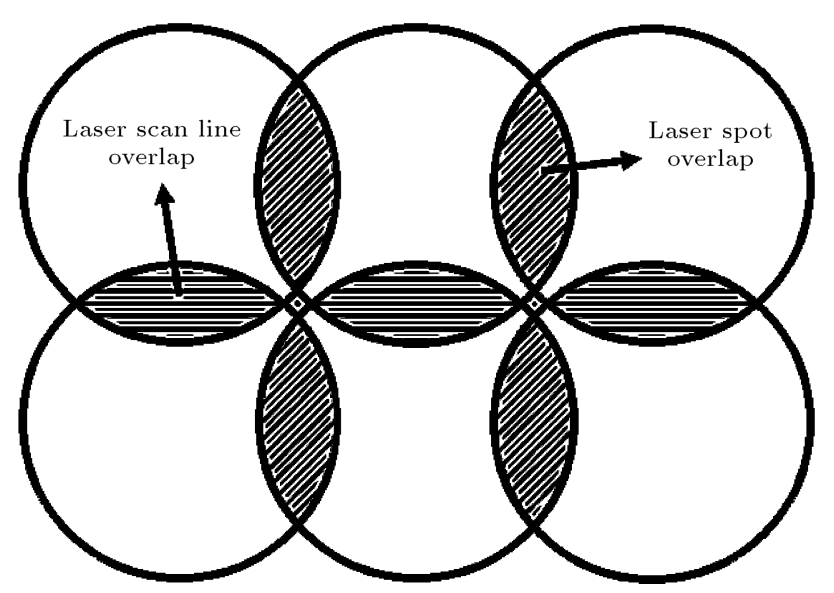

Figure 5. Schematic view of laser spot overlapping. 


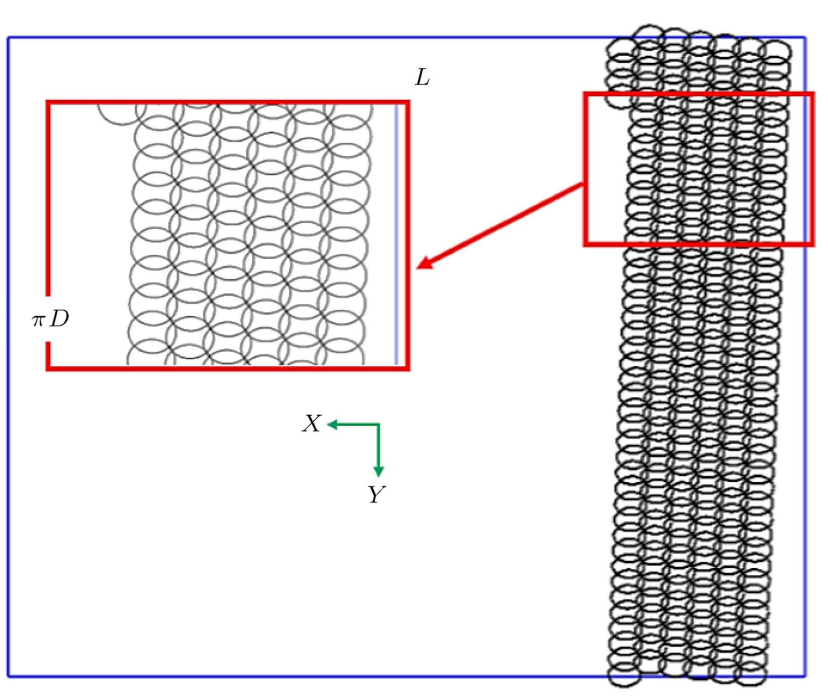

Figure 6. A $2 \mathrm{D}$ schematic view of laser spots distribution pattern in LAT.

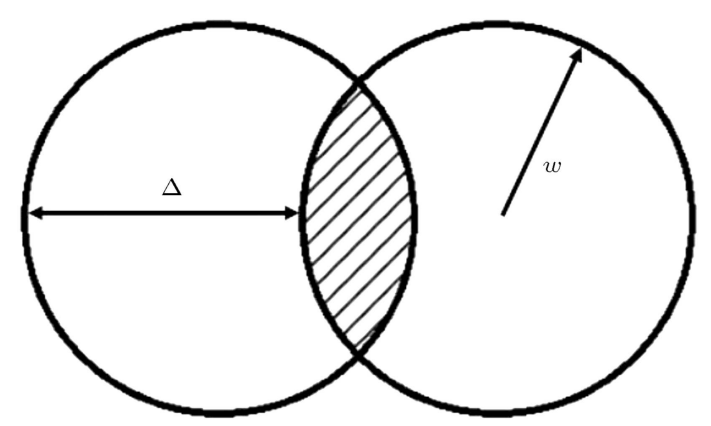

Figure 7. Schematic of laser spot overlapping for two successive laser spots.

of relative velocity of laser over the plane is as follows:

$$
\overrightarrow{V_{L}}=\frac{F \omega}{2 \pi} \hat{I}+R \omega \hat{J}
$$

where $F$ is the translation of laser along feed direction per revolution. In addition, the angle between $\vec{V}_{L}$ and the $Y$-axis is as follows:

$$
\beta=\tan ^{-1}\left(\frac{F}{2 \pi R}\right) .
$$

The time interval between two successive pulses is $1 / H$. Thus, the distance between two successive pulses can be calculated by multiplying the time interval by the magnitude of $\vec{V}_{L}$ as follows:

$$
\Delta_{L}=\frac{\omega}{H} \sqrt{R^{2}+\frac{F^{2}}{4 \pi^{2}}} .
$$

Therefore, the laser spot overlap rate can be written as follows:

$$
\delta_{L}=\left\{\begin{array}{ccc}
O R\left(w, \Delta_{L}\right) & \text { if } & \Delta_{L}<2 w \\
0 \% & \text { if } & \Delta_{L} \geq 2 w
\end{array}\right.
$$

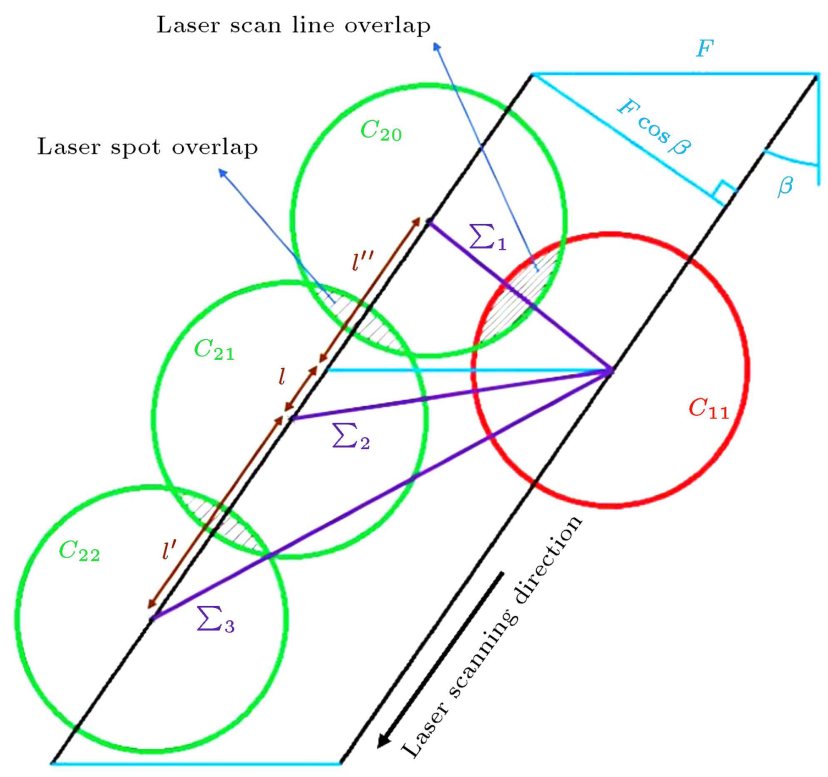

Figure 8. Schematic of laser scan line overlapping in LAT.

\subsubsection{Laser scan line overlap rate}

Figure 8 represents a schematic of laser scan line overlapping in LAT. In the figure, circle $C_{11}$ shows one of the laser spots from the first revolution. Circle $C_{21}$ from the second revolution is the laser spot corresponding to circle $C_{11}$ from the first revolution. In addition, circles $C_{20}$ and $C_{22}$ are the previous and the next spots of circle $C_{21}$ in the second revolution, respectively. It can be seen from the figure that $\sum_{1}$, $\sum_{2}$, and $\sum_{3}$ are distances between centers of three circle pairs of $\left(C_{11}, C_{20}\right),\left(C_{11}, C_{21}\right)$, and $\left(C_{11}, C_{22}\right)$, respectively. Moreover, the distance between two lines that belong to the first and second revolutions equals $F \cos \beta$. On the other hand, the number of laser spots occurring in each revolution is as follows:

$$
O=\left[\frac{2 \pi H}{\omega}\right]
$$

where [ ] denotes the floor function. Since $2 \pi H / \omega$ is a real number, there is a time interval between the last laser spot of a revolution and the end of the revolution, which can be represented as follows:

$$
\epsilon=\frac{2 \pi}{\omega}-\frac{O}{H} .
$$

By using Eq. (20), the time-shift between two corresponding laser spots from two successive revolutions can be expressed as follows:

$$
\Delta t=\frac{1}{H}-\epsilon=\frac{1}{H}\left(1+\left[\frac{2 \pi H}{\omega}\right]\right)-\frac{2 \pi}{\omega} .
$$

Thus, the distance-shift between two corresponding laser spots from two successive revolutions is as 
follows (see Figure 8):

$$
\begin{gathered}
l=\left|\overrightarrow{V_{L}}\right| \Delta t=\left(\frac{\omega}{H}\left(1+\left[\frac{2 \pi H}{\omega}\right]\right)-2 \pi\right) \\
\sqrt{R^{2}+\frac{F^{2}}{4 \pi^{2}}}
\end{gathered}
$$

where $\left|\overrightarrow{V_{L}}\right|$ is the magnitude of vector $\overrightarrow{V_{L}}$. In addition, the lengths of lines $l^{\prime}$ and $l^{\prime \prime}$ from Figure 8 are given by:

$$
\begin{aligned}
& l^{\prime}=\Delta_{L}, \\
& l^{\prime \prime}=\Delta_{L}-l .
\end{aligned}
$$

In addition, $\sum_{1}, \sum_{2}$, and $\sum_{3}$ can be calculated as follows:

$$
\begin{aligned}
& \sum_{1}=\sqrt{F^{2}+l^{\prime \prime 2}-2 F l^{\prime \prime} \sin \beta}, \\
& \sum_{2}=\sqrt{F^{2}+l^{2}+2 F l \sin \beta}, \\
& \sum_{3}=\sqrt{F^{2}+\left(l+l^{\prime}\right)^{2}+2 F\left(l+l^{\prime}\right) \sin \beta} .
\end{aligned}
$$

A flowchart of the calculation of laser scan line overlapping rate $\left(\delta_{S}\right)$ in LAT is shown in Figure 9 . It is observed in this figure that if $\sum_{1} \geq 2 w$ and $\sum_{2} \geq 2 w$, then $\delta_{S}=0 \%$. In addition, if $\sum_{1} \geq 2 w$ and $\sum_{2}<2 w$, then $\delta_{S}=O R\left(w, \sum_{2}\right)$. On the other hand, if $\sum_{1}<2 w$ and $\sum_{2} \geq 2 w$, then $\delta_{S}=$
$O R\left(w, \sum_{1}\right)$. Moreover, for overlapping conditions of $\sum_{1}<2 w$ and $\sum_{2}<2 w$, if $\sum_{3} \geq 2 w$ and $\delta_{L}=0 \%$, then $\delta_{S}=O R\left(w, \sum_{1}\right)$. In addition, for two other conditions (if $\sum_{1}<2 w, \sum_{2}<2 w$, and $\sum_{3}<2 w$ ) and (if $\sum_{1}<2 w, \sum_{2}<2 w, \sum_{3} \geq 2 w$, and $\delta_{L}>$ $0 \%$ ), extracting an exact formulation to calculate $\delta_{S}$ is complicated due to geometrical difficulties; thus, numerical methods should be applied. In fact, $\delta_{L}$ is obtained for all operational conditions, whereas $\delta_{S}$ cannot be formulated for some cases. In these cases, Figure 8 may be used to calculate $\delta_{S}$ via numerical integration.

Finally, a procedure for calculating pulsed laser overlapping rates for the LAT process can be developed based on the discussion in Section 3.4.

\section{Results and discussion}

Table 1 shows the experimental operating conditions for the laser heating of SCFS ceramic workpieces. For all tests, the initial temperature of the workpiece equals the ambient air temperature. The axial distance between the center of the thermometer beam and the workpiece free end is fixed (the thermometer location). The pulse frequency of Nd:YAG laser, the spot diameter of the laser beam incident on the surface of the workpiece, and the normal distance between the head of the laser and the workpiece surface are $90 \mathrm{~Hz}, 3.5 \mathrm{~mm}$, and $15 \mathrm{~mm}$, respectively. The pulse duration of the laser is $2.5 \mathrm{~ms}$.

The thermometer picks up the average temperature of the workpiece surface in its spot area. On the other hand, the computed results of the finite-

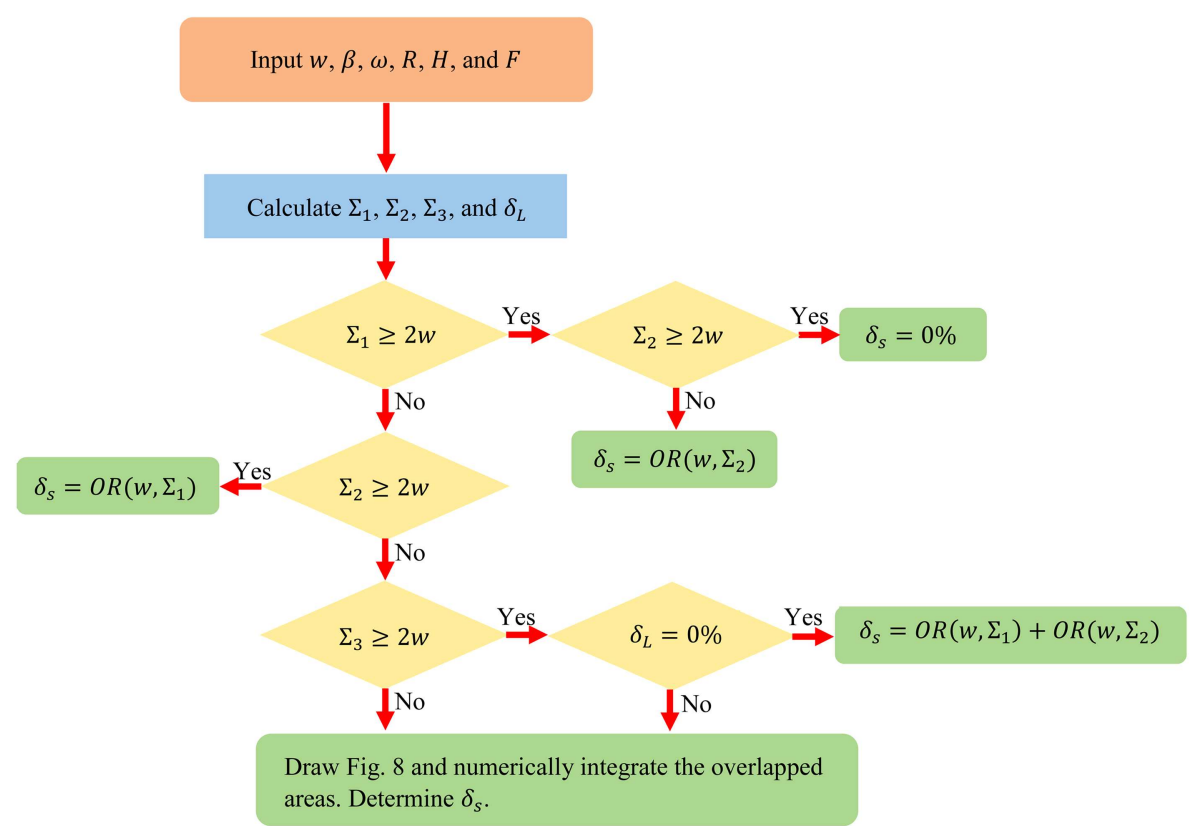

Figure 9. Flowchart for calculation of laser scan line overlapping rate in LAT. 
Table 1. Experimental operating conditions for the laser heating of SCFS ceramics.

\begin{tabular}{cccccc}
\hline Test & Power (W) & $\begin{array}{c}\text { Rotational } \\
\text { speed }(\mathbf{r p m})\end{array}$ & $\begin{array}{c}\text { Feed } \\
(\mathbf{m m} / \mathbf{r e v})\end{array}$ & $\begin{array}{c}\text { Initial temperature } \\
\left({ }^{\circ} \mathbf{C}\right)\end{array}$ & $\begin{array}{c}\text { Thermometer location } \\
(\mathbf{m m})\end{array}$ \\
\hline 1 & 100 & 115 & 0.104 & 23.50 & 10.0 \\
2 & 200 & 115 & 0.325 & 25.00 & 8.1 \\
3 & 300 & 115 & 0.104 & 26.50 & 9.4 \\
\hline
\end{tabular}

Table 2. Experimental operating conditions for the laser heating of SCFS ceramics using the absorptive coating.

\begin{tabular}{cccccc}
\hline Test & $\begin{array}{c}\text { Power } \\
(\mathbf{W})\end{array}$ & $\begin{array}{c}\text { Rotational speed } \\
(\mathbf{r p m})\end{array}$ & $\begin{array}{c}\text { Feed } \\
(\mathbf{m m} / \mathbf{r e v})\end{array}$ & $\begin{array}{c}\text { Initial temperature } \\
\left({ }^{\circ} \mathbf{C}\right)\end{array}$ & $\begin{array}{c}\text { Thermometer location } \\
(\mathbf{m m})\end{array}$ \\
\hline A1 & 100 & 115 & 0.104 & 26.00 & 8.4 \\
A2 & 100 & 190 & 0.325 & 29.50 & 10.9 \\
A3 & 100 & 300 & 0.522 & 26.40 & 8.9 \\
A4 & 200 & 115 & 0.325 & 22.90 & 8.5 \\
A5 & 200 & 190 & 0.522 & 26.90 & 9.4 \\
A6 & 300 & 115 & 0.522 & 22.90 & 10.3 \\
A7 & 300 & 300 & 0.325 & 27.80 & 10.3 \\
\hline
\end{tabular}

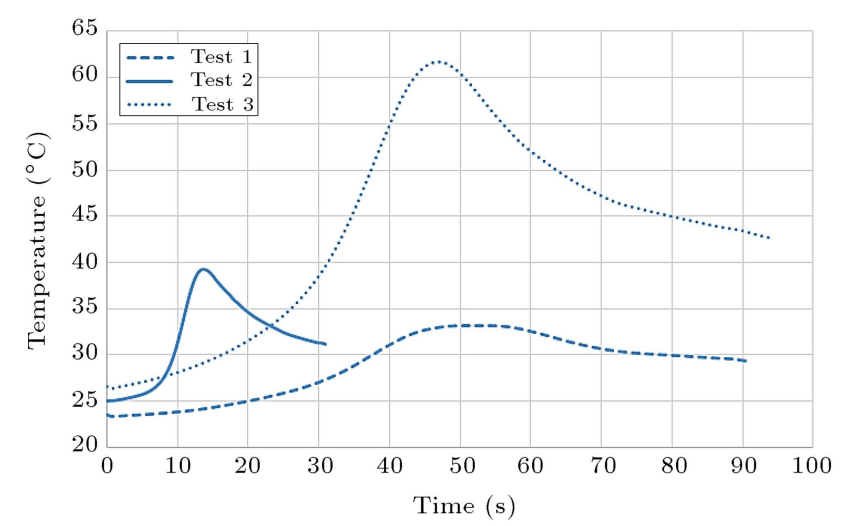

Figure 10. Surface temperature histories for the experimental operating conditions listed in Table 1.

element analysis show nodal temperatures. To compare these results with experimental results, a comparable temperature measurement must be obtained from the simulation. For this purpose, temperatures are averaged over nodes located in the area on the meshed surface corresponding to the thermometer spot. In addition, a moving average filter is used to smooth experimental and numerical results by removing shortterm fluctuations.

Figure 10 depicts experimentally measured surface temperature histories at the fixed location of the thermometer for Tests 1-3 (see Table 1). The figure shows that the temperature rises to its peak value in each case when the laser beam passes the thermometer fixed location followed by a drop when the laser beam passes. It is also observed that the maximum value of workpiece surface temperature is around $65^{\circ} \mathrm{C}$ (corresponding to Test 3 shown in Figure 10), which is a relatively insignificant increase. This is attributed to the low absorptivity and high reflectivity of SCFS ceramics. For reducing the surface reflectivity of SCFS ceramics, the workpiece surface is coated by spraying an oil-based black paint to achieve a higher surface temperature in laser heating processes. Table 2 presents the experimental operating conditions for the laser heating of SCFS ceramic workpieces using the absorptive coating.

\subsection{Experimental determination of the absorptivity}

Since the coated paint in these experiments is oilbased, the paint has limited durability and is detached from the ceramic surface when surface temperature rises beyond a certain value. Furthermore, if laser beam overlaps with all or a part of the previously irradiated area, the absorptivity of the workpiece surface decreases. Thus, it can be concluded that the absorptivity increases with the feed velocity ( $V=$ $F \omega / 2 \pi)$ of the laser beam. On the other hand, for the same experimental operating conditions, the durability of the paint reduces by increasing the laser power $(P)$; therefore, the absorptivity decreases. In fact, power and feed velocity of the laser exert opposite effects on the absorptivity. To find the trend of the absorptivity variations in terms of the ratio between power and feed velocity $(P / V)$, three tests from Table 2 with different $P / V$ ratios are selected (Tests $\mathrm{A} 1, \mathrm{~A} 2$, and $\mathrm{A} 4$ ). In each of these three tests, the objective is to minimize the difference between the experimental and numerical maximum temperatures as follows:

$$
\min \left(\left|T_{m e}-T_{m n}\right|\right)
$$


Table 3. The absorptivity of Tests A1, A2, and A4 from Table 2 .

\begin{tabular}{ccc}
\hline Test & $\boldsymbol{P} / \boldsymbol{V}(\mathbf{W . s} / \mathbf{m})$ & $\boldsymbol{\alpha}(\boldsymbol{\%})$ \\
\hline A1 & 501672 & 36.8 \\
A2 & 97165 & 56.7 \\
A4 & 321046 & 42.3 \\
\hline
\end{tabular}

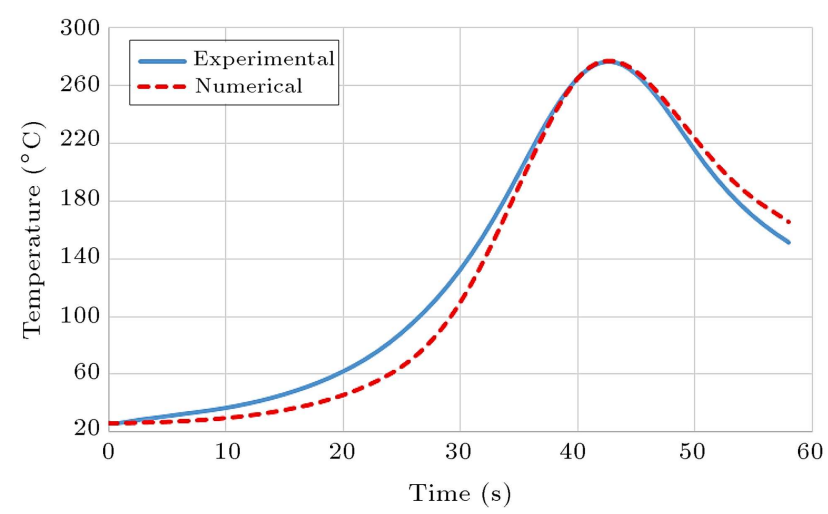

Figure 11. Experimental and numerical surface temperature histories for Test A1 from Table 2.

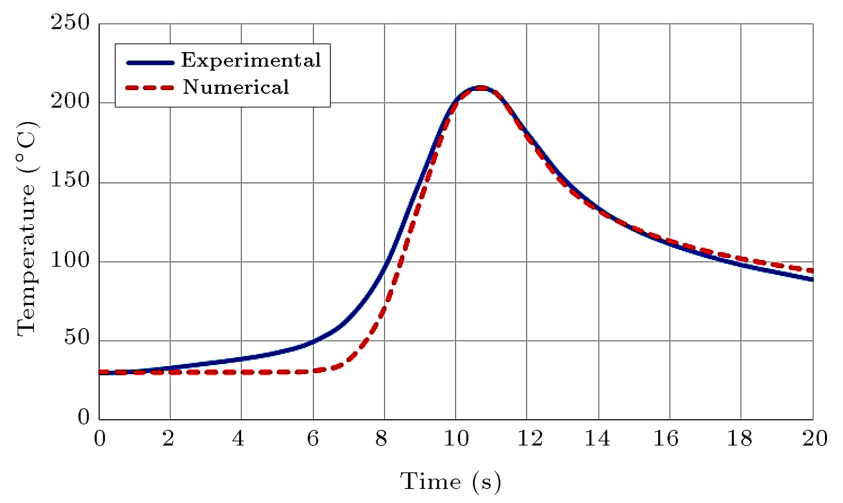

Figure 12. Experimental and numerical surface temperature histories for Test A2 from Table 2.

where $T_{m e}$ and $T_{m n}$ are the maximum temperatures of experimental tests and numerical simulations, respectively. Table 3 lists the absorptivity in these three tests. According to Table 3, the absorptivity of the ceramic surface changes significantly for different $P / V$ ratios. Moreover, experimental and numerical surface temperature histories of these three tests are depicted in Figures 11-13. A quadratic polynomial curve, as a function of $P / V$ ratio, fits the absorptivity values of Table 3 as follows:

$$
\alpha=(6.74 e-11)\left(\frac{P}{V}\right)^{2}-(8.96 e-5)\left(\frac{P}{V}\right)+\begin{array}{r}
64.83 . \\
(29)
\end{array}
$$

This equation is used to estimate the absorptivity in the remaining experimental operating conditions of Table 2 so that it can be used in the simulations.

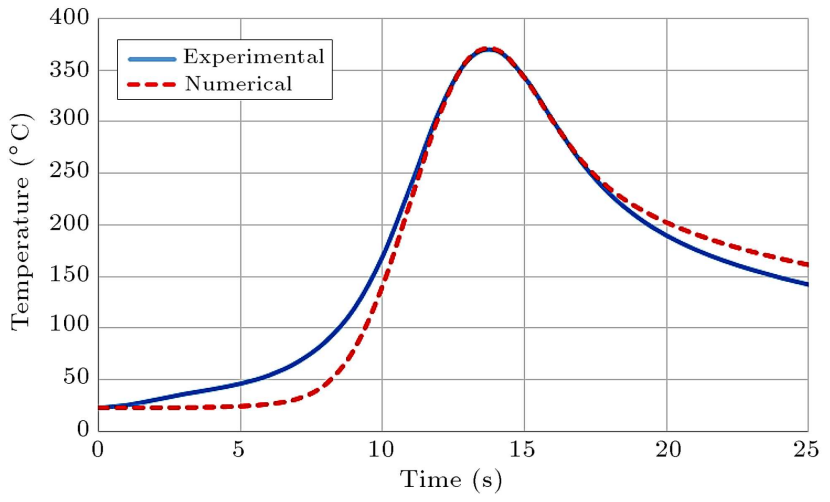

Figure 13. Experimental and numerical surface temperature histories for Test A4 from Table 2.

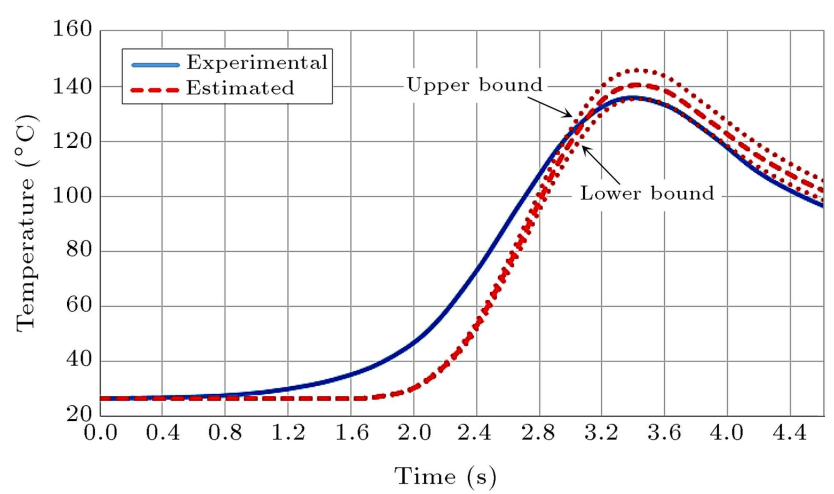

Figure 14. Experimental and numerical surface temperature histories for Test A3 from Table 2.

To demonstrate the effectiveness of the coating in surface absorption, the temperatures achieved in Tests 1 and 2 of Table 1 are compared with those of Tests A1 and A4 of Table 2. These tests are done under similar conditions, except that in the latter cases, surface coating is applied. It is observed from Figure 10 that while the maximum increase rates of the surface temperatures of Tests 1 and 2 from Table 1 are respectively around $10^{\circ} \mathrm{C}$ and $14^{\circ} \mathrm{C}$, these temperatures are risen to $251^{\circ} \mathrm{C}$ and $346^{\circ} \mathrm{C}$ for Tests $\mathrm{A} 1$ and $\mathrm{A} 4$ of Table 2, respectively, as shown in Figures 11 and 13 . Therefore, using coating has a significant effect on the surface temperature increase.

\subsection{Validation of finite element model}

Using the determined absorptivity for different experimental operating conditions, the finite element simulations under various operating conditions are carried out. In order to validate the thermal model, experimental surface temperature histories in the remaining operating conditions of Table 2 are compared with numerical ones in Figures 14-17. Due to the uncertainty associated with determination of the absorptivity, numerical surface temperature histories for a $\pm 3 \%$ uncertainty bound are also plotted in these figures (dotted lines). Experimental and numerical 


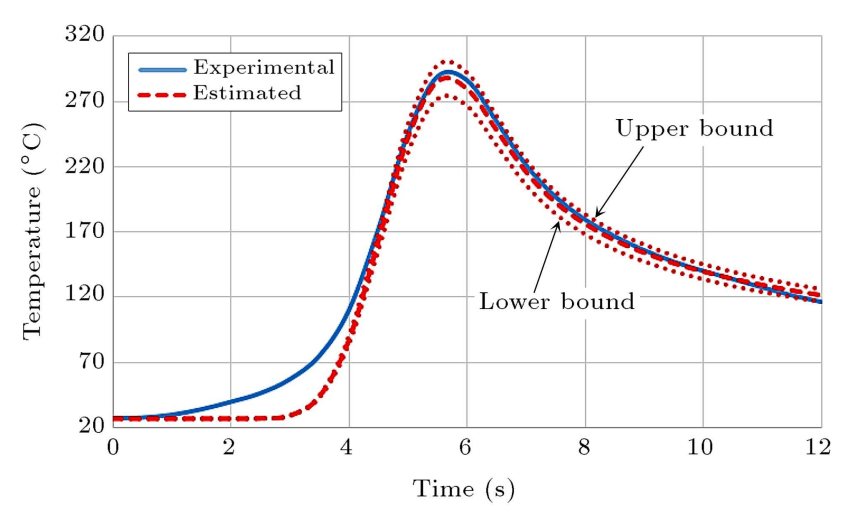

Figure 15. Experimental and numerical surface temperature histories for Test A5 from Table 2.

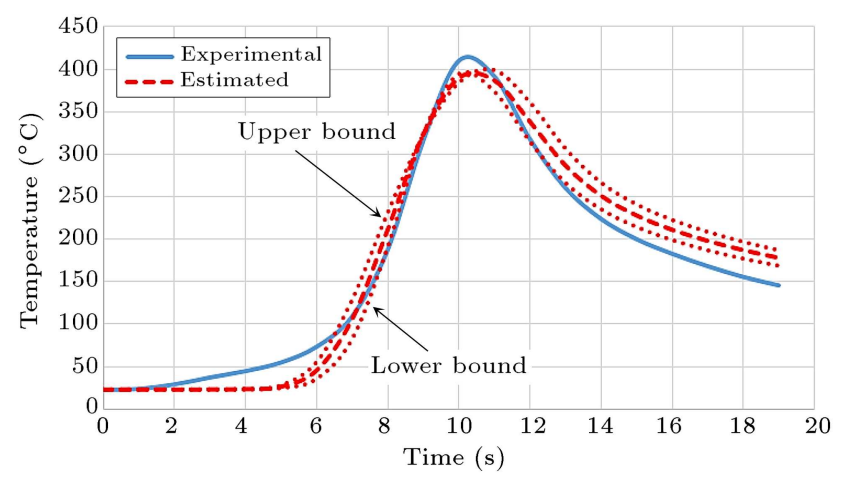

Figure 16. Experimental and numerical surface temperature histories for Test A6 from Table 2.

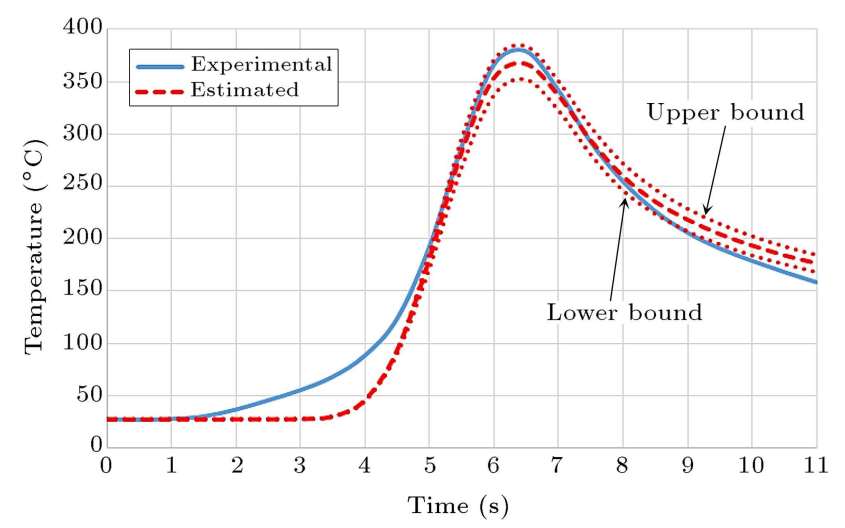

Figure 17. Experimental and numerical surface temperature histories for Test A7 from Table 2.

surface temperatures follow similar overall trends. In general, the peak temperature of experimental results falls within the upper and lower bounds, except for Test A6, in which the peak temperature of experiment is slightly higher than that of upper bound and has a $4 \%$ error with respect to the simulations (Figure 16). Consequently, these results confirm the validity of the finite-element simulation based on experimental results.

It can be seen from Figures 11-17 that the experimental surface temperature has higher values in comparison with the numerical ones, before reaching the peak temperature. On the other hand, beyond that point, the experimental surface temperatures are reduced faster than the numerical ones. From these figures, it is observed that the maximum and minimum temperatures increase to around $387^{\circ} \mathrm{C}$ and $109^{\circ} \mathrm{C}$ for Tests A6 and A3, respectively. It is illustrated in Figures 11-17 that by increasing $V$ at constant laser power, the peak temperature of the workpiece decreases. For example, the peak temperature for Test A1 with a rotational speed of $115 \mathrm{rpm}$ is $276^{\circ} \mathrm{C}$, while that is $135^{\circ} \mathrm{C}$ for Test $\mathrm{A} 3$ with a rotational speed of $300 \mathrm{rpm}$.

\subsection{Effect of laser spot overlapping on the absorptivity and temperature rise}

Figure 18 depicts workpiece surface under different laser heating overlapping patterns at various laser powers. It can be observed from this figure that various operational conditions create different overlapping patterns on the surface of workpiece. Some of operational conditions cannot detach the paint from the surfaces; thus, it is easy to predict that the absorptivity of these tests (such as Tests A2, A3, and A5) is higher than that of the other tests. In addition, laser spot overlap and laser scan line overlap rates for Tests A1-A7 are tabulated in Table 4. It can be seen in this table that

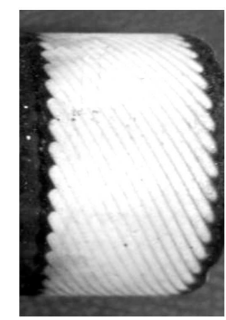

A1

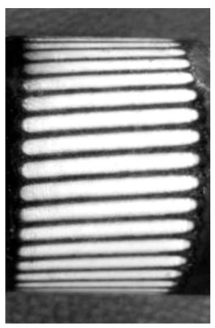

A4

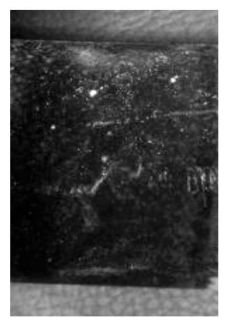

A2

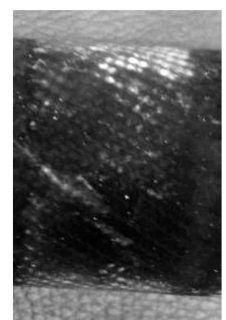

A5

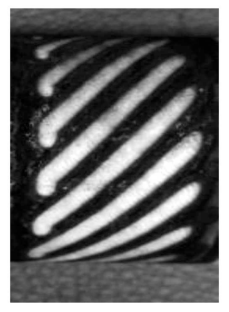

A 7

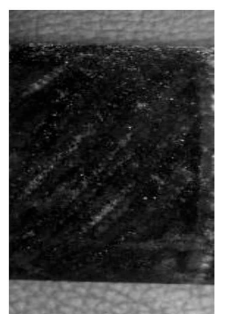

A3

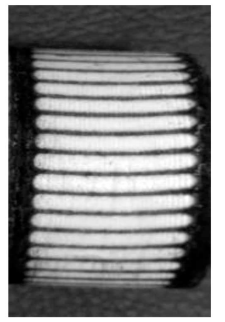

A 6
Figure 18. Images of overlapping patterns for the laser heating in LAT. 
Table 4. Laser spot overlap rates, laser scan line overlap rates, and the predicted absorptivity for Tests A1-A7.

\begin{tabular}{cccccc}
\hline Test & Power $(\mathbf{W})$ & $\boldsymbol{\delta}_{\boldsymbol{L}}(\boldsymbol{\%})$ & $\boldsymbol{\delta}_{\boldsymbol{S}}(\boldsymbol{\%})$ & $\boldsymbol{\alpha}(\boldsymbol{\%})$ & Peak temperature $\left({ }^{\circ} \mathbf{C}\right)$ \\
\hline A1 & 100 & 21.68 & 97.45 & 36.8 & 276 \\
A2 & 100 & 0 & 65.76 & 56.7 & 208 \\
A3 & 100 & 0 & 81.08 & 57.5 & 135 \\
A4 & 200 & 21.68 & 91.53 & 42.3 & 370 \\
A5 & 200 & 0 & 63.18 & 54.8 & 289 \\
A6 & 300 & 21.68 & 85.80 & 43.3 & 410 \\
A7 & 300 & 0 & 88.19 & 50.1 & 379 \\
\hline
\end{tabular}

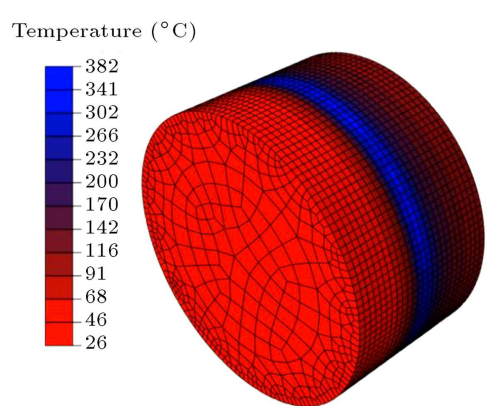

(a)

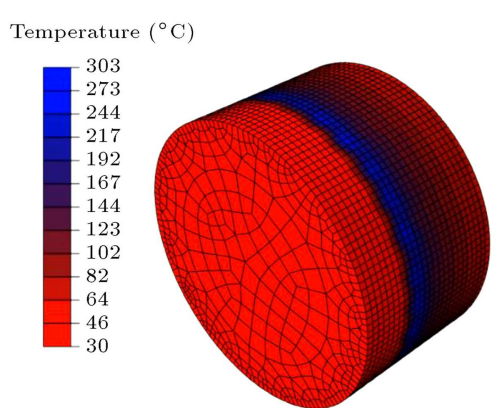

(b)

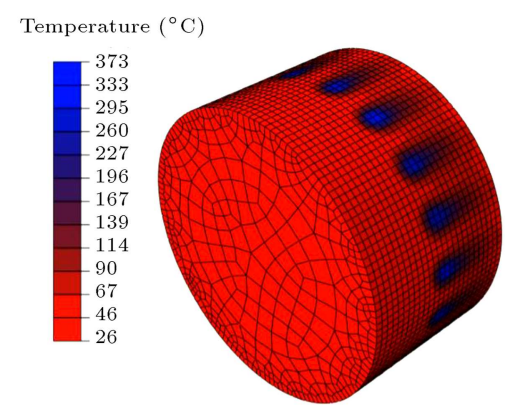

(c)

Figure 19. Surface temperature distribution due to the laser heating of the workpiece: (a) Test A1 after 42.9 sec, (b) Test A2 after $11 \mathrm{sec}$, and (c) Test A3 after $3.3 \mathrm{sec}$.

for Tests A2, A3, A5, and A7, laser spot overlap rates are zero. Considering the absorptivity of these four tests and their corresponding images in Figure 18, it is observed that laser power has a stronger effect on the absorptivity than laser scan line overlap rate does. For example, the value of $\delta_{S}$ for Test A 5 is lower than those for Tests A2 and A3, although the laser power is higher for Test A5. Thus, with increasing the laser power at zero laser spot overlap rate, the absorptivity decreases. On the other hand, it is expected that if either $\delta_{L}$ or $\delta_{S}$ increases independently, the absorptivity decreases. It is noted that each pair of tests (A1, A2), (A4, A5), and $(\mathrm{A} 6, \mathrm{~A} 7)$ has the same laser power, and $\delta_{L}$ and $\delta_{S}$ have higher values for Tests A1, A4, and A6 than those for the other tests $\left(\delta_{S}\right.$ has nearly the same value for Tests A6 and A7). By comparing the results of these pairs of tests, it can be concluded that the absorptivity of Tests A1, A4, and A6 is lower than that for the other tests.

Similar to the influence of laser spot overlapping on the absorptivity as discussed above, the pulse overlapping also affects both the peak temperature and temperature distribution. It can be seen from Table 4 that for Tests A2 and A3 (with different values of $\left.\delta_{S}\right)$, the peak temperature for Test A3 is lower than that for Test A2, because $\delta_{S}$ is higher in Test A3. In fact, when circle $C_{21}$ or $C_{20}$ completely (or nearly complete) overlaps with circle $C_{11}$ (i.e., $\delta_{L}$ equals zero and $\delta_{S}$ has a high value), a wide part of the workpiece surface remains non-irradiated. Due to these reasons, the thermometer indicates a lower temperature for Test A3 than that for Test A2, because it measures the temperature by averaging its spot area, including both irradiated and non-irradiated areas. By increasing $\delta_{L}$, overlapping between two subsequent laser spots results in high concentration of the induced heat, which in turn increases the temperature of the workpiece surface as compared to when there is no overlapping between successive laser spots. In this regard, Tests A1, A4, and A6 have higher peak temperatures than the other tests from Table 4 with the same laser power.

To provide a detailed view of numerical simulations, Figure 19 displays surface temperature distribution of the workpiece resulting from finite element analysis utilizing ABAQUS/Standard for Tests A1A3. It is observed in this figure that maximum temperatures for these three tests are higher than peak temperatures measured in the tests. Furthermore, it is seen that only a fraction of surface is irradiated in Test A3 (see Figure 19(c)), and a large part of the surface area is not irradiated. As a result, the thermometer shows a lower temperature in Test A3 than that in the two other tests (A1 and A2). However, maximum temperature for Test A3 calculated from the numerical model is higher than that for Test A2. This is because $\delta_{S}$ in Test A3 is higher than that in Test A2. By increasing $\delta_{S}$, the concentration of laser beam irradiation over overlapping zone increases, whereas by 
reducing $\delta_{S}$, a larger part of surface area is irradiated by the laser. Therefore, the thermometer reads a higher temperature in Test A2 than that in Test A3. On the other hand, the maximum temperature from finite element method and the peak temperature from the thermometer for Test A1 are higher than those for Tests A2 and A3. This is due to the fact that $\delta_{L}$ has a significant value, which results in the surface with a more uniform temperature distribution as compared to tests with zero $\delta_{L}$. Furthermore, $\delta_{S}$ for Test A1 is higher than that for Tests A2 and A3, causing a higher concentration of laser energy over overlapping zone.

Finally, it is noted that the best operating condition in LAT is to have a uniform temperature distribution and a sufficiently high temperature. The uniformity of temperature distribution guarantees that the machinability of all parts of the workpiece is improved, while the higher maximum temperature, the better the machinability of the workpiece. Based on the above discussion, it is observed that a uniform temperature distribution is provided when $\delta_{L}$ and $\delta_{S}$ have high values (see Figure 19). On the other hand, the maximum temperature increases when $\delta_{L}, \delta_{S}$, and the laser power increase. As a result, operational conditions of Test A6 are the best among Tests A1-A7.

\section{Conclusion}

A 3D finite-element analysis of heat transfer in LAM of SCFS ceramics was presented in which temperaturedependent thermo-physical properties of this ceramic were employed. Since surfaces of SCFS ceramics reflected more than $95 \%$ of radiant energy, an oil-based black paint was sprayed as coating on the workpiece surfaces in order to increase absorptivity. By fitting experimental results, a formulation for the absorptivity of the surface was obtained as a quadratic polynomial function of $P / V$ ratio. It was shown that the utilized technique significantly increased the absorptivity of the workpiece surfaces and provided conditions for achieving much higher surface temperatures. The numerical model was validated through comparison with the experimental results obtained from laser heating of SCFS ceramics using a pulsed Nd:YAG laser.

The validated heat transfer model provided a tool to study the effect of laser parameters and cutting conditions on the efficiency of the LAM process and to optimize these parameters. In the actual LAM process, the cutting tool is located in the thermometer place and cuts the material at the measured temperature. The present thermal model should be combined with a cutting model to provide a full analysis of the LAM.

Using the thermal model, pulse overlapping rates for LAT procedure were formulated, and the effect of laser spot overlapping on the absorptivity was investigated. In addition, the influence of overlapping on the temperature distribution and the peak temperature was studied. It was shown that better operational conditions for laser assisted turning were achieved when $\delta_{L}, \delta_{S}$, and the laser power had higher values.

\section{References}

1. Westkämper, E. "Grinding assisted by Nd:YAG lasers", CIRP Ann-Manuf. Techn., 44(1), pp. 317-320 (1995).

2. Tian, Y., Wu, B., Anderson, M., and Shin, Y.C. "Laser-assisted milling of silicon nitride ceramics and inconel 718", J. Manuf. Sci. Eng., 130(3), pp. 031013031013 (2008).

3. Wiedenmann, R. and Zaeh, M.F. "Laser-assisted milling-process modeling and experimental validation", CIRP J. of Manuf. Sci. and Tech., 8, pp. 70-77 (2015).

4. Lei, S., Shin, Y.C., and Incropera, F.P. "Experimental investigation of thermo-mechanical characteristics in laser-assisted machining of silicon nitride ceramics", $J$. Manuf. Sci. Eng., 123(4), pp. 639-646 (2000).

5. Bejjani, R., Shi, B., Attia, H., and Balazinski, M. "Laser assisted turning of Titanium metal matrix composite", CIRP Ann-Manuf. Techn., 60(1), pp. 6164 (2011).

6. Rebro, P.A., Shin, Y.C., and Incropera, F.P. "Laserassisted machining of reaction sintered mullite ceramics", J. Manuf. Sci. Eng., 124(4), pp. 875-885 (2002).

7. Germain, G., Dal Santo, P., and Lebrun, J.L. "Comprehension of chip formation in laser assisted machining", Int. J. Mach. Tool. Manufact., 51(3), pp. 230-238 (2011).

8. Zhang, G., Jiang, C., Zhang, S., Wang, Y., Chen, $\mathrm{X}$., and $\mathrm{Yu}$, L. "An experimental investigation of laser assisted drilling process", Mater. Res. Innov., 19 (sup8), pp. S8-889-S888-894 (2015).

9. Chang, C.-W. and Kuo, C.-P. "An investigation of laser-assisted machining of $\mathrm{Al}_{2} \mathrm{O}_{3}$ ceramics planing", Int. J. Mach. Tool. Manufact., 47(3-4), pp. 452-461 (2007).

10. Rebro, P.A., Shin, Y.C., and Incropera, F.P. "Design of operating conditions for crackfree laser-assisted machining of mullite", Int. J. Mach. Tool. Manufact., 44(7), pp. 677-694 (2004).

11. Chang, C.-W. and Kuo, C.-P. "Evaluation of surface roughness in laser-assisted machining of aluminum oxide ceramics with Taguchi method", Int. J. Mach. Tool. Manufact., 47(1), pp. 141-147 (2007).

12. Tian, Y. and Shin, Y.C. "Thermal modeling for laserassisted machining of silicon nitride ceramics with complex features", J. Manuf. Sci. Eng., 128(2), pp. 425-434 (2005). 
13. Kim, J.-D., Lee, S.-J., and Suh, J. "Characteristics of laser assisted machining for silicon nitride ceramic according to machining parameters", J. Mech. Sci. Technol., 25(4), pp. 995-1001 (2011).

14. Pfefferkorn, F.E., Shin, Y.C., Tian, Y., and Incropera, F.P. "Laser-assisted machining of magnesia-partiallystabilized zirconia", J. Manuf. Sci. Eng., 126(1), pp. 42-51 (2004).

15. Pfefferkorn, F.E., Lei, S., Jeon, Y., and Haddad, G. "A metric for defining the energy efficiency of thermally assisted machining", Int. J. Mach. Tool. Manufact., 49(5), pp. 357-365 (2009).

16. Rozzi, J.C., Pfefferkorn, F.E., Shin, Y.C., and Incropera, F.P. "Experimental evaluation of the laser assisted machining of silicon nitride ceramics", $J$. Manuf. Sci. Eng., 122(4), pp. 666-670 (1999).

17. Tian, Y. and Shin, Y.C. "Multiscale finite element modeling of silicon nitride ceramics undergoing laserassisted machining", J. Manuf. Sci. Eng., 129(2), pp. 287-295 (2006).

18. Dong, X. and Shin, Y.C. "Multiscale finite element modeling of alumina ceramics undergoing laserassisted machining", J. Manuf. Sci. Eng., 138(1), p. 011004 (2016).

19. Rozzi, J.C., Pfefferkorn, F.E., Incropera, F.P., and Shin, Y.C. "Transient thermal response of a rotating cylindrical silicon nitride workpiece subjected to a translating laser heat source, Part I: comparison of surface temperature measurements with theoretical results", J. Heat Transfer., 120(4), pp. 899-906 (1998).

20. Rozzi, J.C., Incropera, F.P., and Shin, Y.C. "Transient thermal response of a rotating cylindrical silicon nitride workpiece subjected to a translating laser heat source, Part II: Parametric effects and assessment of a simplified model", J. Heat Transfer., 120(4), pp. 907915 (1998).

21. Rozzi, J.C., Incropera, F.P., and Shin, Y.C. "Transient, three-dimensional heat transfer model for the laser assisted machining of silicon nitride: II. Assessment of parametric effects", Int. J. Heat Mass Transfer., 43(8), pp. 1425-1437 (2000).

22. Rozzi, J.C., Pfefferkorn, F.E., Incropera, F.P., and Shin, Y.C. "Transient, three-dimensional heat transfer model for the laser assisted machining of silicon nitride: I. Comparison of predictions with measured surface temperature histories", Int. J. Heat Mass Transfer., 43(8), pp. 1409-1424 (2000).

23. Pfefferkorn, F.E., Incropera, F.P., and Shin, Y.C. "Heat transfer model of semi-transparent ceramics undergoing laser-assisted machining", Int. J. Heat Mass Transfer., 48(10), pp. 1999-2012 (2005).

24. Smith, D.G. and Chowdary, M. "The fracture toughness of slip-cast fused silica", Mater. Sci. Eng., 20, pp. 83-88 (1975).
25. Harris, J.N. and Welsh, E.A., Fused Silica Design Manual, Defense Technical Information Center (1973).

26. Roostaei, H. and Movahhedy, M.R. "Analysis of heat transfer in laser assisted machining of slip cast fused silica ceramics", Proc. CIRP., 46, pp. 571-574 (2016).

27. Huang, L.-J., Li, B.-J., and Ren, N.-F. "Enhancing optical and electrical properties of Al-doped $\mathrm{ZnO}$ coated polyethylene terephthalate substrates by laser annealing using overlap rate controlling strategy", Ceram. Int., 42(6), pp. 7246-7252 (2016).

28. Hafiz, A.M.K., Bordatchev, E.V., and Tutunea-Fatan, R.O. "Influence of overlap between the laser beam tracks on surface quality in laser polishing of AISI H13 tool steel", J. Manuf. Process., 14(4), pp. 425434 (2012).

29. Hu, Y.X. and Yao, Z.Q. "Fem simulation of residual stresses induced by laser shock with overlapping laser spots", Acta Metall. Sin. (Engl. ED), 21(2), pp. 125132 (2008).

30. Samant, A.N. and Dahotre, N.B. "Three-dimensional laser machining of structural ceramics", J. Manuf. Process., 12(1), pp. 1-7 (2010).

31. Kuar, A., Doloi, B., and Bhattacharyya, B. "Modelling and analysis of pulsed Nd: YAG laser machining characteristics during micro-drilling of zirconia $(\mathrm{ZrO}$ 2)", Int. J. Mach. Tool. Manufact., 46(12), pp. 13011310 (2006).

32. Dahotre, N.B. and Harimkar, S., Laser Fabrication and Machining of Materials, Springer Science \& Business Media (2008).

33. Mohanty, A.K., Tawfek, A.A., and Prasad, B.V.S.S.S. "Heat transfer from a rotating cylinder in crossflow", Exp. Therm. Fluid Sci., 10(1), pp. 54-61 (1995).

34. Bohn, M. and Wang, K.-Y., Experiments and Analysis on the Molten-Salt Direct-Contact Absorption Receiver Concept, in, Solar Energy Research Inst., Golden, CO, USA (1986).

35. Fleming, J., Fused Silica Manual, Georgia Inst. of Tech., Atlanta. Engineering Experiment Station (1964).

\section{Biographies}

Hossein Roostai obtained his BSc and MSc degrees in Mechanical Engineering from Iran University of Science and Technology (IUST), Tehran, Iran in 2010 and 2012, respectively. He is currently pursuing his $\mathrm{PhD}$ degree in Mechanical Engineering at Sharif University of Technology, Tehran, Iran. At present, he is researching on laser-assisted machining of ceramics.

Mohammad Reza Movahhedy received his PhD degree from the University of British Columbia in 2000. He is currently a Professor of Manufacturing at the Department of Mechanical Engineering at Sharif University of Technology, Tehran, Iran. $\mathrm{He}$ is the 
Head of Precision Manufacturing Lab, and his current research interest includes machining processes and laser processing and additive manufacturing.

Reza Shoja Razavi received his $\mathrm{PhD}$ degree from
Isfahan University of Technology, Iran in 2007. He is currently a Professor in the field of Materials Engineering in Malek-Ashtar University. His research interests include laser material processing, surface engineering, and corrosion. 